\title{
NEW MANITOBA LICHENS
}

JAMES L. PARKER, Box 99, Gilbert Plains, Manitoba, ROL 0X0.

In the years 1977 and 1978 I collected a number of lichens in the Duck Mountain vicinity. Specimens were sent to the National Museum of Natural Sciences in Ottawa, and identified by P. Y. Yong. C. D. Bird's A Catalogue of the Lichens Reported from Alberta, Saskatchewan and Manitoba is the standard authority on lichen distribution in those provinces. The identifications were submitted to Dr. Bird, who writes that the following listed appear to be additions to the reported flora of Manitoba.

The Cowan specimens were collected in thin pine forest, on or along the Campbell Glacial Beach. Gilbert Plains specimens are from broad-leaved woods. Other collections are mainly coniferous forest.

The following list gives the specific name as determined by Yong, the medium in which the lichen was growing, and the nearest geographical feature listed in the Manitoba Gazetteer. All specimens and notes were donated to the National Museum of Natural Sciences.

Cladonia bacillaria (Ach.) Nyl. Pinus. Cowan.

C. macilenta Hoffm. Pinus. Cowan. Peltigera elizabethae Gyelin. Debris. Gilbert Plains.

Physconia detersa (Nyl.) Poelt. Abies. Baldy Mountain.

Usnea sorediifera (Arn.) Lynge aggregate. Picea. Head of Shanty Creek.

U. subfloridana Stirt. Picea. Head of Shanty Creek.

U. filipendula Stirt. Picea. Singush Lake.

Phaeophysicia pusilloides (Zahlbr.) Essl. Betula. Gilbert Plains.

Ramalina intermedia (Del. ex Nyl.) Nyl. Picea. Singush Lake.

I wish to thank Dr. Yong for the identifications, and Dr. Bird for searching the Manitoba records.

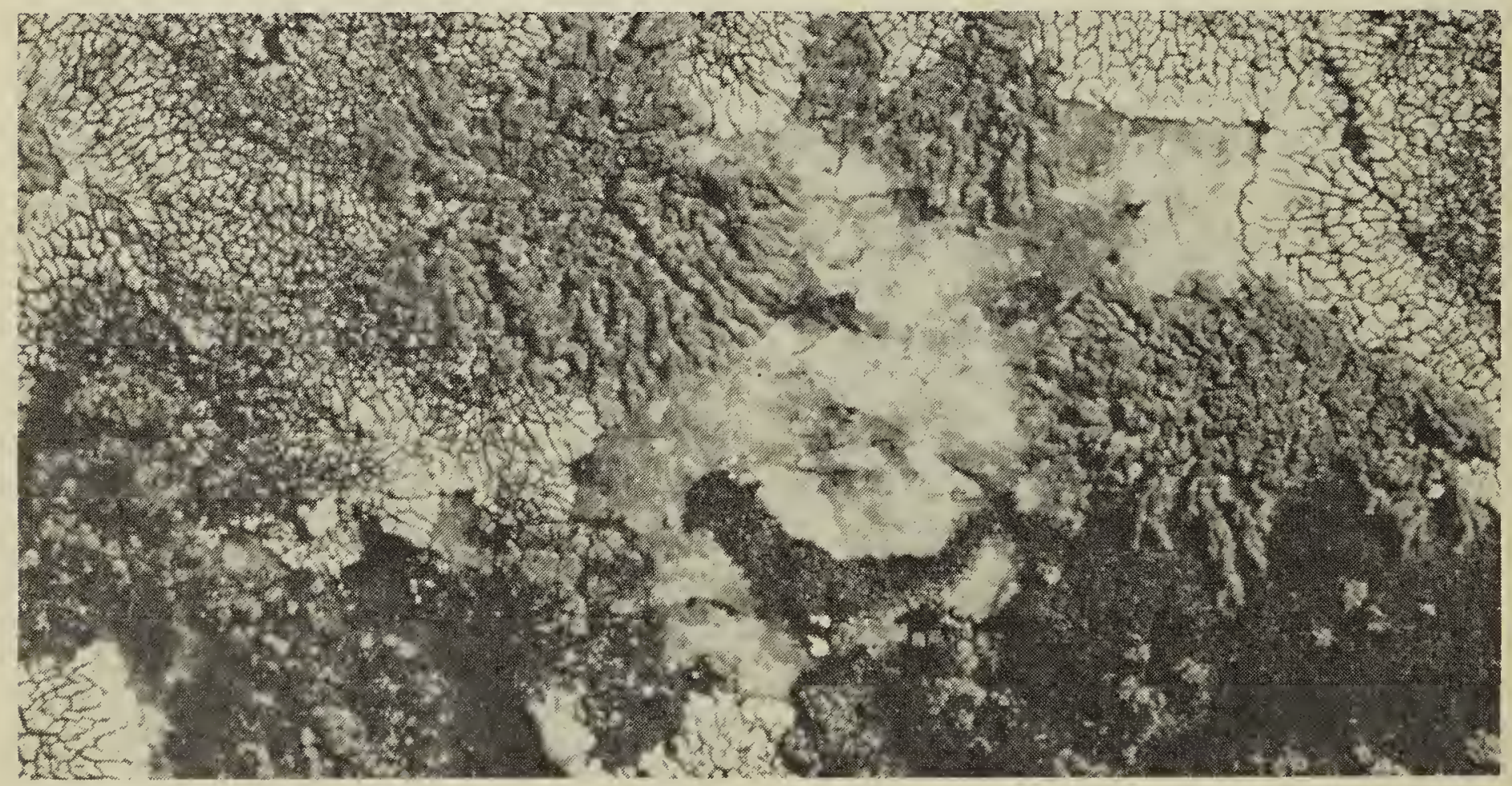

